\title{
Potential of a Population of Domestic Heat Pumps to Provide Balancing Service
}

\author{
Mazin MUHSSIN, Liana CIPCIGAN, Nick JENKINS, Meng CHENG, Zeyad Assi OBAID
}

\begin{abstract}
This paper investigates the model of aggregated heat pumps as a source of the flexible load in Great Britain. A thermal model of a domestic heat pump was presented. A decentralised temperature control algorithm was proposed to control the building temperature, and heat pump's ON and OFF cycles. Seven case studies were used to identify the suitable number of individual heat pump models that can be aggregated to accurately represent the projected number of heat pumps connected to the 2030 GB's power system. The simulation results revealed that an aggregated model of 5,000 individual heat pumps was accurately representing the entire number of heat pumps in the Great Britain power system. Also, the power consumption of a group of heat pumps was examined in response to the grid frequency. Simulation results showed that the power consumption of aggregated heat pumps was successfully controlled in response to a frequency change. The controlled heat pumps reduced the dependency on the frequency service obtained by expensive peaking generators.
\end{abstract}

Keywords: demand side response; frequency control; heat pumps

\section{INTRODUCTION}

The adversities associated with the increase of the intermittence generations come from the fact that the traditional power systems were designed based on large controllable synchronous generators. The renewable generation could disrupt the operation of conventional method that balances the power generation with the demand. For this reason, new balancing methods should be developed to maintain the generation and supply equal at all the time. At present, the balancing services are mainly provided in the supply side, through different types of services such as primary, secondary, tertiary services [1-3].

Nowadays, there are great efforts to engage the consumers to the balancing mechanism between generation and demand. Many ways were used to control the energy of consumers. For example, a statistical method was proposed for managing the balance between demand and supply using demand side management [4-6]. Demand Side Response (DSR) is another approach that is used to provide balancing services to the system such as primary frequency control and spinning reserve [7-9]. DSR is used to switch some loads OFF and/or ON or having their power consumption increased/decreased when there is a power mismatch between the generation and the demand $[10,11]$. Unfortunately, not all the types of load can take part in DSR mechanism. Hence, only the flexible loads that could vary according to an external signal can be engaged in the DSR service. Demand response can be obtained from the loads that can operate in a degree of independence from the users, such as fridges, washing machines, and heat pumps $[12,13]$. Due to the thermal storage characteristics, thermal loads have the potential to provide balancing services, having no impact on the overall system performance. For instance, heat pumps and air-conditioning devices can be turned ON/OFF for a period of time without affecting the pre-defined range of the room temperature [14]. Further details about the flexible appliances in the UK are given in [15].

This paper focuses on the usage of space heating load, such as heat pumps as a source of the controlled load in GB. The GB's power system is under demand increasing pressure, especially heat pumps and electric vehicles. However, increasing the load could also be of benefit to the grid if they are used in the right way [16]. Regarding the heat pumps, there were used three future scenarios in GB [12]; the low and high uptake scenarios which are based on National Grid's slow progression and Gone Green scenarios [17], and the medium uptake which is based on [18]. According to the medium uptake scenario [16], the frequency response that could be obtained from heat pumps could correspond to the $30 \%$ of frequency response requirements estimated in 2030 in GB.

The thermal storage characteristic of the buildings allows the thermal units engaged with them, such as heat pumps and ventilation heat recovery system, to provide frequency response services. That is, they could receive a low or high-frequency signal from the grid and are switched ON or OFF for a period of time accordingly without disrupting the building temperature [19-21]. Space heating/cooling energy demand and efficient thermal comfort were investigated in different homes categories [22] and [23].

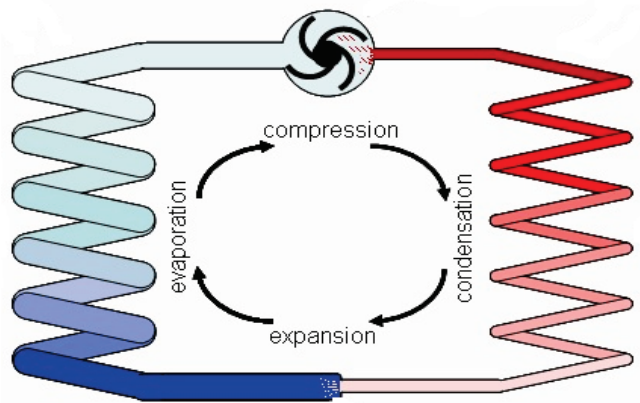

Figure 1 Diagram of the heat pump operation [25]

This paper provided an extended format to the previous work in [24]. A model of the population of the domestic building was developed. The power consumption of a group of heat pumps was controlled according to the grid frequency.

\section{THERMAL DYNAMIC MODEL OF A SINGLE HEAT PUMP}

The diagram of a heat pump is shown in Fig.1. The heat gain from the environment takes place in the heat pump's evaporator. The liquid refrigerant inside the 
evaporator is boiled and evaporated even in lowtemperature degrees. The resulting gaseous is then compressed through the compressor causing its pressure and temperature to rise. The heated refrigerant passes through the condenser, and the heat is then released to the house. The gaseous is then converted into a hot liquid, which goes through an expansion valve causing its temperature to decrease. It can once again absorb the heat from the external environment, and the cycle of the heat pump starts again.

The operation of different types of heat pumps is well detailed in [26, 27]. In this section, a simplified lumped thermal parameters model is introduced as shown in Fig. 2. In this model, $C_{\mathrm{a}}\left(\mathrm{J} /{ }^{\circ} \mathrm{C}\right)$ and $C_{\mathrm{m}}\left(\mathrm{J} /{ }^{\circ} \mathrm{C}\right)$ represent the air and mass heat capacity, $Q_{\mathrm{hp}}(\mathrm{W})$ is the heat rate flow of heat pump unit, $U \mathrm{~A}_{\text {insul }}\left(\mathrm{W} /{ }^{\circ} \mathrm{C}\right)$ is the standby heat loss coefficient to the ambient, $U A_{\text {mass }}\left(\mathrm{W} /{ }^{\circ} \mathrm{C}\right)$ is the heat loss coefficient between indoor air and mass, $T_{\mathrm{o}}\left({ }^{\circ} \mathrm{C}\right)$ is the ambient temperature, whilst $T_{\text {in }}\left({ }^{\circ} \mathrm{C}\right)$ and $T_{\mathrm{m}}\left({ }^{\circ} \mathrm{C}\right)$ are the house and house mass temperatures respectively [28].

The thermal model can be mathematically modelled by calculating the Ordinary Differential Equations (ODE). The ordinary differential equations descriptions of the model can be found by calculating the variation of the building and building mass temperature. The variation of building temperature is represented by a first order differential equation as shown in Eqs. (1) - (3), where $Q_{\mathrm{rm}}$ is the heat transfer between the building and building mass, and $Q_{\text {ro }}$ is the heat transfer from the building to the outside ambient.

$$
\begin{aligned}
& C_{\mathrm{a}} \frac{\mathrm{d} T_{\mathrm{in}}}{\mathrm{d} t}=-Q_{\mathrm{ro}}-Q_{\mathrm{rm}}+Q_{\mathrm{hp}} \\
& C_{\mathrm{a}} \frac{\mathrm{d} T_{\mathrm{in}}}{\mathrm{d} t}=-\frac{1}{R_{1}}\left(T_{\mathrm{in}}-T_{\mathrm{o}}\right)-\frac{1}{R_{2}}\left(T_{\mathrm{in}}-T_{\mathrm{m}}\right)+Q_{\mathrm{hp}} \\
& \frac{\mathrm{d} T_{\mathrm{in}}}{\mathrm{d} t}=-\left(\frac{1}{R_{1} C_{\mathrm{a}}}+\frac{1}{R_{2} C_{\mathrm{a}}}\right) T_{\mathrm{in}}+\frac{1}{R_{2} C_{\mathrm{a}}} T_{\mathrm{m}}+\frac{1}{R_{1} C_{\mathrm{a}}} T_{\mathrm{o}}+\frac{Q_{\mathrm{hp}}}{C_{\mathrm{a}}}
\end{aligned}
$$

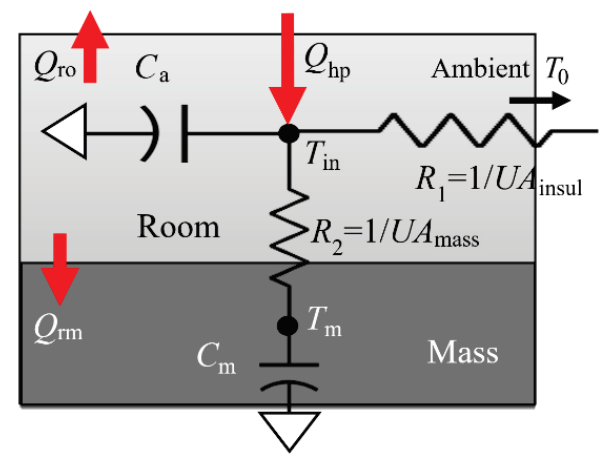

Figure 2 Lumped thermal parameters model of a domestic heat pump unit

The balance equation of the building mass is given in Eq. (4) and Eq. (5).

$C_{\mathrm{m}} \frac{\mathrm{d} T_{\mathrm{m}}}{\mathrm{d} t}=Q_{\mathrm{rm}}$

$\frac{\mathrm{d} T_{\mathrm{m}}}{\mathrm{d} t}=\frac{1}{R_{2} C_{\mathrm{m}}} T_{\text {in }}-\frac{1}{R_{2} C_{\mathrm{m}}} T_{\mathrm{m}}$
Typically, the building mass thermal storage $C_{\mathrm{m}}$ and thermal resistance $R_{2}$ are large, i.e. the variation of mass temperature $\mathrm{d} T_{\text {in }} / \mathrm{d} t$ is small.

The differential equations in Eq. (3) and Eq. (5) can be further simplified by neglecting the temperature variation in Eq. (5). Thus, the equivalent model that conforms to the measured indoor temperature curve is presented in Eq. (6).

$\frac{\mathrm{d} T_{\text {in }}}{\mathrm{d} t}+k_{1} T_{\text {in }}=k_{2}$

where $k_{1}=1 / R_{1} C_{\mathrm{a}}$ and $k_{2}=\left(U A_{\text {insul }} T_{\mathrm{o}}+Q_{\mathrm{hp}}\right) / C_{\mathrm{a}}$. Eq. (6) has two possible solutions depending on the heat pump state $s_{\mathrm{c}}$. For instance, when $s_{\mathrm{c}}=1$, the heat pump power rate is assumed to be $Q_{\mathrm{hp}}$, whilst $Q_{\mathrm{hp}}$ is equal to zero when $s_{\mathrm{c}}=0$. The two solutions of Eq. (6) are introduced in Eqs. (7) and (8).

$$
\begin{aligned}
& T_{\text {in }}^{t+1}=T_{\mathrm{o}}+Q_{\mathrm{hp}} R_{1}-\left(T_{\mathrm{o}}+Q_{\mathrm{hp}} R-T_{\text {initial }}^{t}\right) \cdot \mathrm{e}^{-\frac{\Delta t}{R_{\mathrm{l}} C_{\mathrm{a}}}} \cdot S_{\mathrm{c}}=1 \\
& T_{\mathrm{in}}^{t+1}=T_{\mathrm{o}}-\left(T_{\mathrm{o}}-T_{\text {initial }}^{t}\right) \cdot \mathrm{e}^{-\frac{\Delta t}{R_{1} C_{\mathrm{a}}}} \cdot S_{\mathrm{c}}=0
\end{aligned}
$$

where $T_{\text {in }}^{t+1}$ refers to the indoor temperature at the time $\mathrm{t}+$ $1\left({ }^{\circ} \mathrm{C}\right), R_{1}\left({ }^{\circ} \mathrm{C} / \mathrm{W}\right)$ denotes the thermal resistance, $\Delta t$ is the step time, $s_{\mathrm{c}}$ is the heat pump's compressor state. The typical ON and OFF periods $t_{\mathrm{on}}$ and $t_{\mathrm{off}}$ are shown in Fig. 3. For the dwelling insulated to typical UK levels, the heating system ON/OFF setpoint temperature range $\left(T_{\min }\right.$, $\left.T_{\max }\right)$ is $19-23{ }^{\circ} \mathrm{C}$ [29]. For this reason, it was assumed that when $s_{\mathrm{c}}=1, T_{\text {in }}$ starts from $T_{\min }=19{ }^{\circ} \mathrm{C}$ at $t_{\text {on }}=0$ minute and increases to reach $T_{\max }=23{ }^{\circ} \mathrm{C}$ at $t_{\mathrm{on}}=30$ minutes.

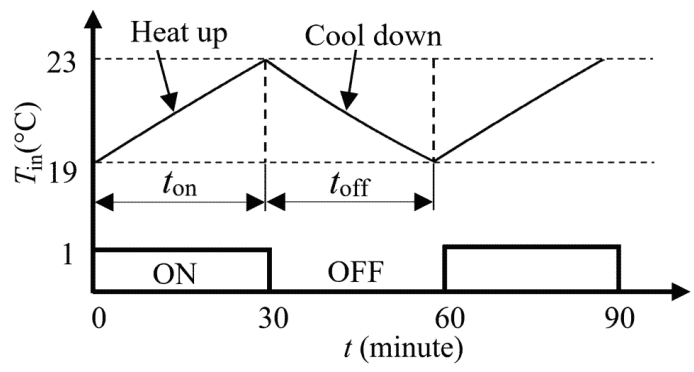

Figure 3 Temperature control of one heat pump unit

Table 1 Number of aggregated heat pump models

\begin{tabular}{|c|c|c|c|}
\hline $\begin{array}{c}\text { Case } \\
\text { study }\end{array}$ & $\begin{array}{c}\text { Number of } \\
\text { individual heat } \\
\text { pump models }\end{array}$ & $\begin{array}{c}\text { Multiplied } \\
\text { number }\end{array}$ & $\begin{array}{c}\text { Simulation time } \\
(\mathrm{sec})\end{array}$ \\
\hline 1 & 100 & 35,000 & 1 \\
\hline 2 & 500 & 7000 & 3 \\
\hline 3 & 1000 & 3500 & 7 \\
\hline 4 & 5000 & 700 & 45 \\
\hline 5 & 10,000 & 350 & 84 \\
\hline 6 & 50,000 & 70 & 332 \\
\hline 7 & 100,000 & 35 & 649 \\
\hline
\end{tabular}

\section{MODELLING WORK AND SIMULATION RESULTS}

The thermal model that is given in Eqs. (7) and (8) was simulated using MATLAB. The initial ON and OFF states of each heat pump unit were randomised to create the load diversity. Each heat pump unit has a power rate of $3 \mathrm{~kW}$ 
[12]. There are expected to be around 3.5 million heat pumps in UK houses by 2030, according to the medium uptake scenario of the Element Energy [16].

Using 3.5 million independent heat pump models is infeasible and complex. However, a smaller number of heat pump models can be utilised and then scaled up by multiplying the power consumption output by a number to represent the total population. The smaller number of heat pump models was considered in seven case studies as shown in Tab. 1. This modelling work was conducted to find the most appropriate case to model the behaviour of all 3.5 million heat pumps.

In the first case study, an aggregated model of 100 individual heat pumps is multiplied by 35,000 to represent the entire population in the GB power system. In this case study, only 100 heat pumps were assigned with different ON and OFF initial time, while 35,000 heat pumps had the same states. Conversely, when case study seven is used, it is an integration of 100,000 heat pump models with different states. By multiplying these aggregated models with 35 to represent all heat pumps, this assumes that only 35 heat pumps have similar states.

Fig. 4. shows the initialization process of a population of 5,000 heat pumps with different temperature and ON/OFF states at an average outdoor temperature $T_{\mathrm{o}}=10$ ${ }^{\circ} \mathrm{C}$.

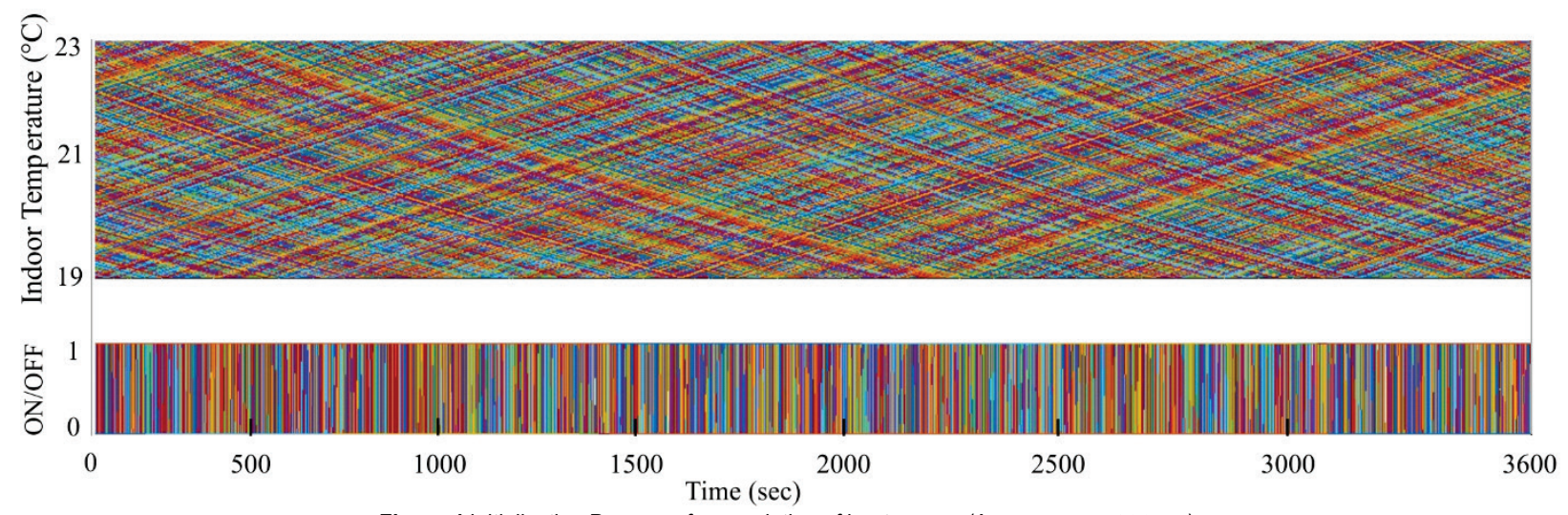

Figure 4 Initialization Process of a population of heat pumps (Average $T_{0}=100{ }^{\circ} \mathrm{C}$ )

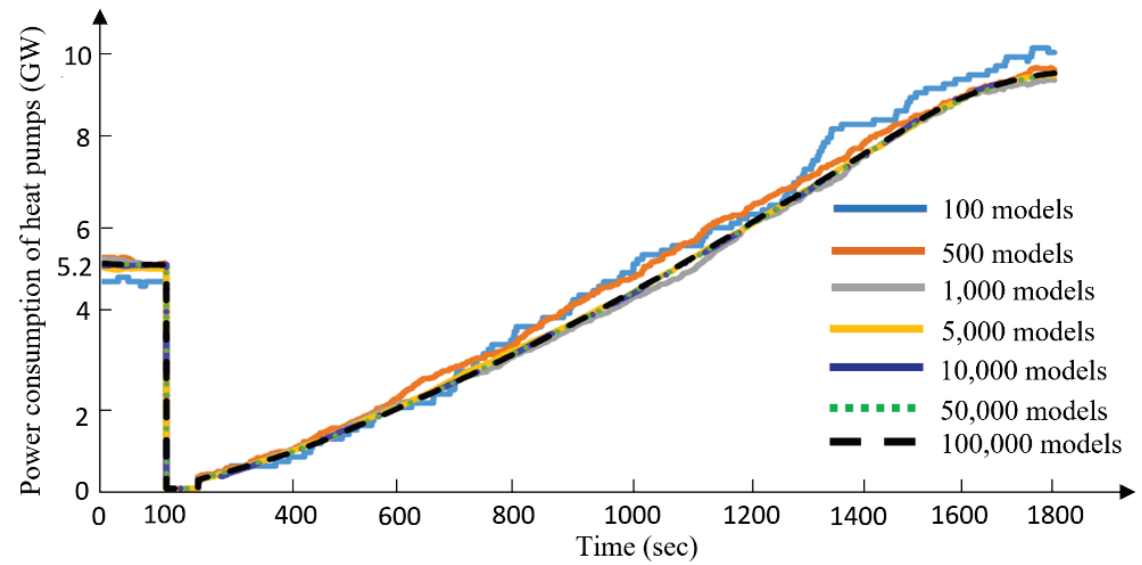

Figure 5 Total power consumption of $3,500,000$ heat pumps obtained from the thermodynamic model

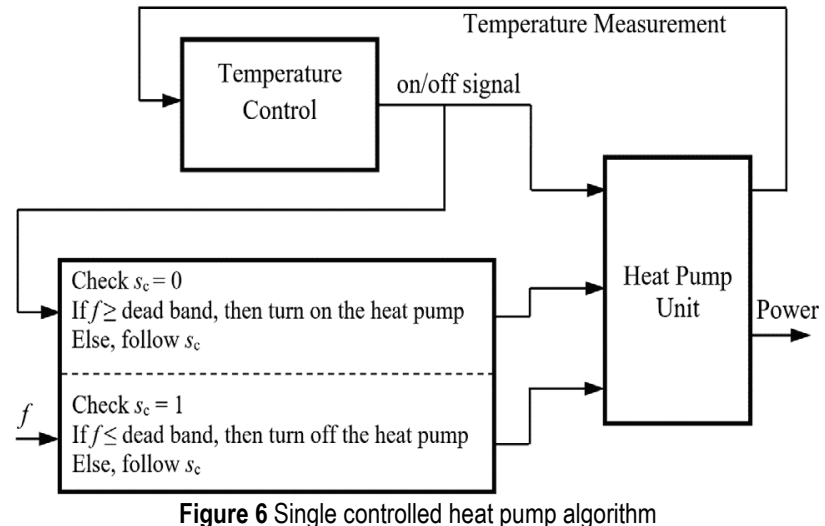

It was assumed that each heat pump unit was equipped with a smart frequency controller that turns the heat pump $\mathrm{ON}$ or $\mathrm{OFF}$ in response to the grid frequency. Fig. 5 compares the total power consumption drawn by the heat pumps in all cases following a drop of power at time 100 sec. It can be seen from the aggregated models of 100, 500 and 1,000 individual heat pump models (case studies 1-3), the power consumption of the heat pumps was very different and not gradual. However, the power consumption of the aggregated models of 5,000, 10,000, 50,000 and 100,000 individual heat pumps (case studies 47) showed a progressive and similar power change. Table 1 shows the simulation time of each model. Based on the accuracy and simulation time of each model, the aggregated model in case study four with 5,000 individual heat pump models is the best model to represent the entire number of heat pumps, for a frequency response study in Great Britain. 


\section{FREQUENCY CONTROLLER}

The frequency control scheme is shown in Fig.6. There are two inputs to the controller: the system frequency $(f)$ and the ON/OFF heat pump state $\left(s_{\mathrm{c}}\right)$. The controller requires monitoring the heat pump states because when the frequency drops, only $\mathrm{ON}$ - heat pumps are able to be switched off. Similarly, when the frequency rises, only OFF-heat pumps can be switched on. If a heat pump is in OFF-state, i.e., $s_{\mathrm{c}}=0$, the controller compares the system frequency with a low-frequency dead-band to generate the final switching signal. When a heat pump is in ON-state $\left(s_{\mathrm{c}}\right.$ $=0$ ), the controller compares the system frequency with a high-frequency dead-band to produce a final switching signal. Considering the inherent ON/OFF cycle of the heat pump presented in Section 2, only half of the total number of heat pumps, connected to the grid, can respond to the frequency signal. The number of heat pumps in ON states was assumed to be equal to the number of heat pumps in OFF-states during the normal operation.

The dynamic control relationship between the system frequency and buildings temperature is not considered in this study. Furthermore, the system frequency was assumed as an external signal.

\subsection{Low-Frequency Event Case Study}

This case study was carried out to examine the behaviour of a population of heat pumps to change their power in response to a low-frequency event. The scenario that was used here involved the integration of one million and two million heat pumps to the model as presented in Tab. 2. The simulations in this case study were performed by inputting a real frequency profile to the model as shown in Fig. 7. The frequency drop (at time $470 \mathrm{sec}$ ) was presumably caused by a loss of power plant. The frequency dead-band,which specified the limit in which the heat pumps take a low-frequency action, was set between 49.5$49.9 \mathrm{~Hz}$. The frequency was assumed to fall to about 49.6 $\mathrm{Hz}$ from $50 \mathrm{~Hz}$ at time $470 \mathrm{~s}$ and recovered to the limit 50$50.1 \mathrm{~Hz}$ at time $500 \mathrm{~s}$. Fig. 8 shows the behaviour of one million controlled heat pumps in response to the frequency drop. It can be seen that 1,500 MW of power consumption drawn by heat pumps was reduced within $5 \mathrm{~s}$ following the frequency incident. A reduction power of $530 \mathrm{MW}$ from heat pumps was obtained within $1 \mathrm{~s}$ following the incident.

Table 1 Number of aggregated heat pumps

\begin{tabular}{|c|c|c|}
\hline \multirow{2}{*}{} & $\begin{array}{c}\text { Low frequency event } \\
\text { scenario } \\
f \leq 49.5-49.9 \mathrm{~Hz}\end{array}$ & $\begin{array}{c}\text { High frequency event } \\
\text { scenario }\end{array}$ \\
& $1,000,000$ & $1,000,000$ \\
\hline \multirow{2}{*}{$\begin{array}{c}\text { Number of heat } \\
\text { pumps }\end{array}$} & $2,000,000$ & $2,000,000$ \\
\cline { 2 - 3 } &
\end{tabular}

Fig. 9 shows the power consumption of two million controlled heat pumps in proportion to the frequency drop. It can be observed that the frequency controller has decreased the total power consumption from heat pumps to $500 \mathrm{MW}$ from $3500 \mathrm{MW}$ within $5 \mathrm{~s}$. Within $1 \mathrm{~s}$ following the event, the total power was reduced by 1,650 MW.

It is noticeable that increasing the number of controlled heat pumps has provided a larger reduction in total power demand. Also, the responsive heat pumps have been responded immediately after the frequency change. It can be concluded that the response obtained from controlled heat pumps has a similar (or even faster) response to that which is obtained from a spinning reserve.

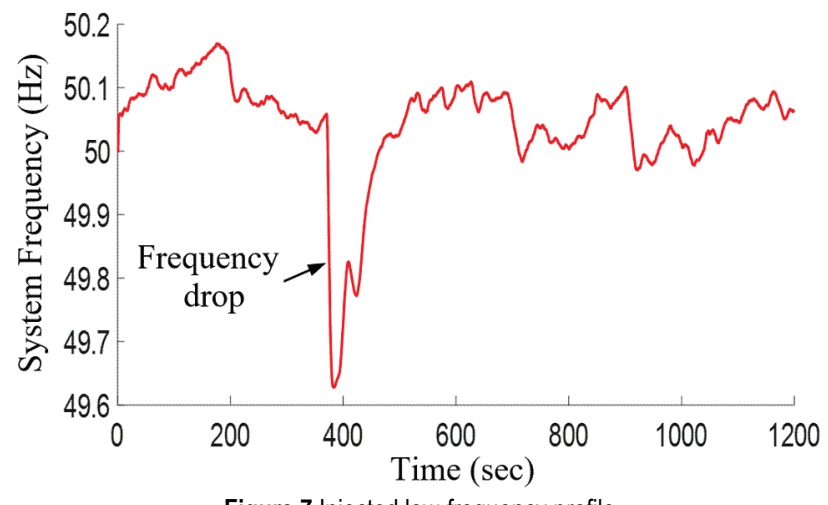

Figure 7 Injected low-frequency profile

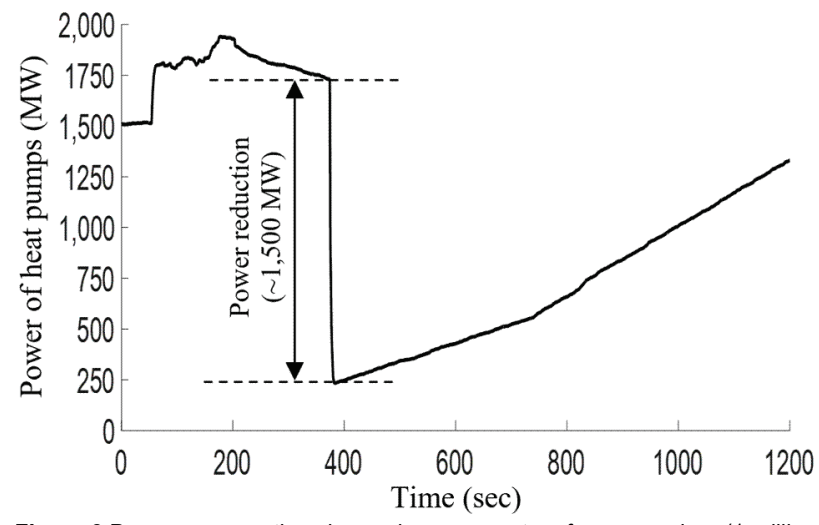

Figure 8 Power consumption change in response to a frequency drop (1-million heat pumps)

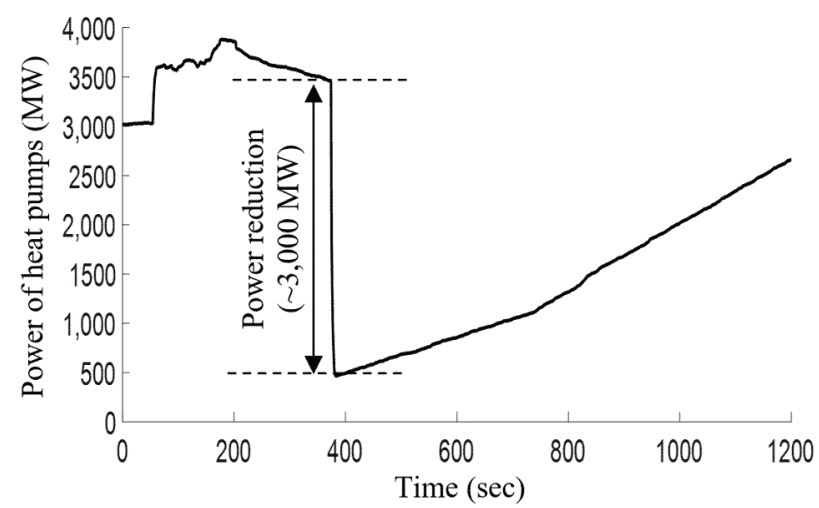

Figure 9 Power consumption change in response to a frequency drop (2million heat pumps)

\subsection{High-Frequency Event Case Study}

This case study was undertaken to alter the heat pumps power in response to a high-frequency event. The scenario which was used here also involved the aggregation of one million and two million heat pumps as shown in Tab. 2 . Simulations were performed by inserting a step change frequency profile to the model, as presented in Fig. 10. The frequency dead-band, in which the heat pumps respond to a high-frequency signal, was set between $50.1-50.5 \mathrm{~Hz}$, where $50 \mathrm{~Hz}$ is the nominal frequency value in the GB power system. 


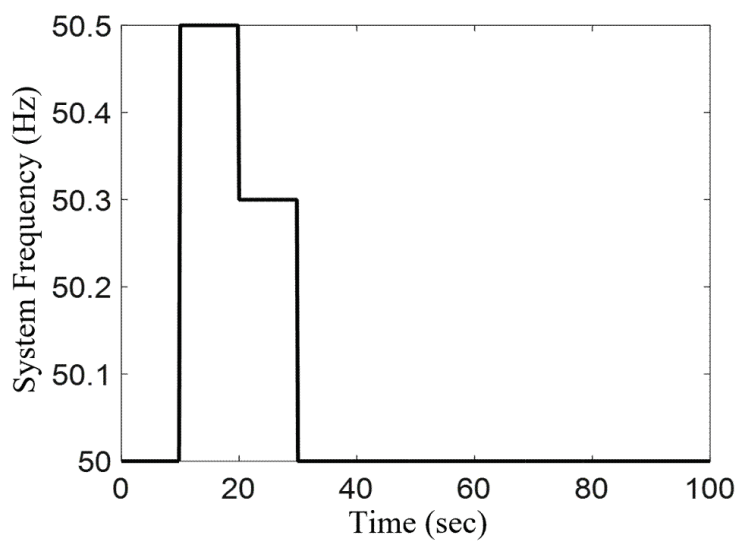

Figure 10 Injected high-frequency profile

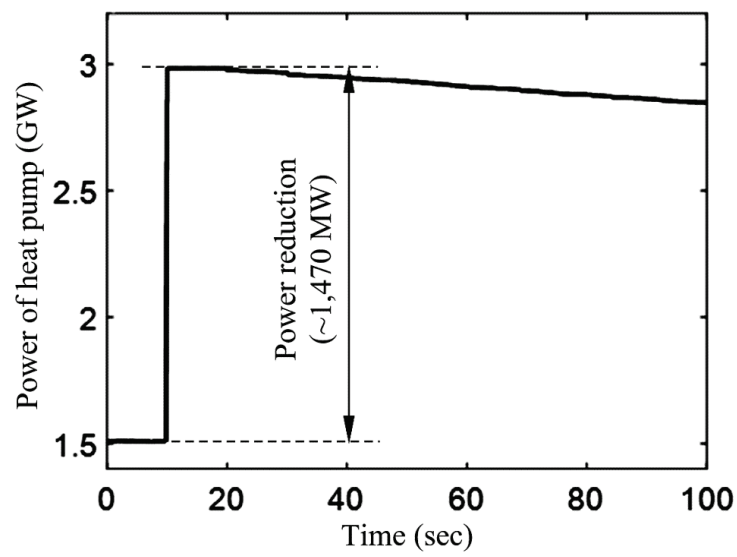

Figure 11 Power consumption change in response to a frequency rise (1-million heat pumps)

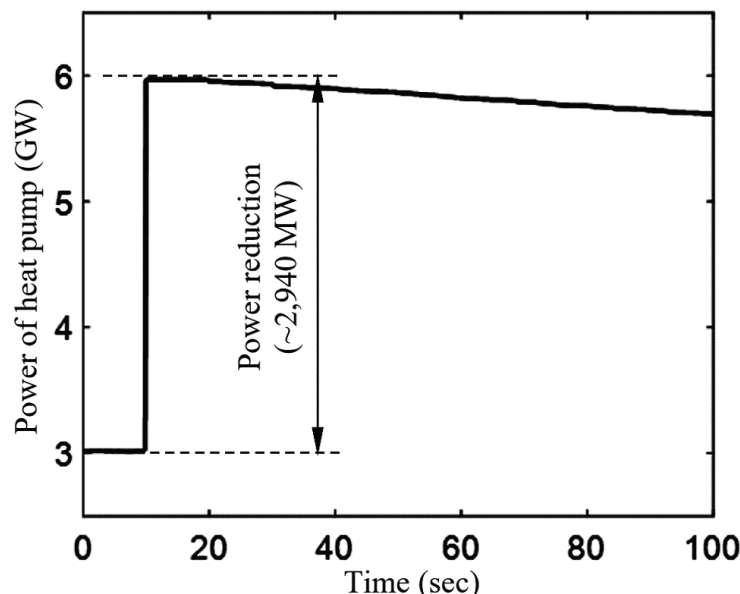

Figure 12 Power consumption change in response to a frequency rise (2-million heat pumps)

When the frequency is increased to $50.5 \mathrm{~Hz}$ at time $10 \mathrm{~s}$, the controller has triggered the heat pumps into OFF state. Therefore, an increase of about $1.47 \mathrm{GW}$ of power consumption from one million heat pumps was obtained, as shown in Fig. 11.

Similarly, with the aggregation of two million heat pumps, shown in Fig. 12, the controller has turned some heat pumps $\mathrm{ON}$, and hence the total power consumption increased to about $2.94 \mathrm{GW}$.

In conclusion, simulation results showed that heat pumps are behaving as flexible loads and can provide a significant balancing service by changing their power consumption in response to the frequency change. Demand response from heat pumps can reduce the overall frequency services that are currently supplied by expensive power plants.

\section{CONCLUSION}

A thermal model of a domestic building equipped with a heat pump unit was presented. An aggregation model of a group of heat pumps was simulated using MATLAB coded function. A 3.5 million heat pumps were assumed in this study, which represents the entire number of domestic heat pumps in GB in 2030. Moreover, an accurate aggregation model that was used for a frequency response provision from all heat pumps in GB was identified. Seven case studies revealed that an aggregated model of 5,000 heat pumps is the most suitable representation for the total number of heat pumps in GB.

Frequency Control algorithm was developed to control the power consumption of heat pumps in response to an external frequency signal. Simulation results showed that controlling the power consumption behaviour of a large number of heat pumps could provide balancing services in a manner similar to or faster than that provided by traditional power generation.

The frequency response obtained from heat pumps depends on the number of heat pumps. Future work will investigate the availability of heat pumps over the time of day.

It is noteworthy to mention that the power consumption of each heat pump unit is small and hence the frequency response depends on the aggregation of a population of heat pumps. The heat pumps can be aggregated with other appliances to obtain larger frequency response service.

\section{Acknowledgements}

The authors would like to acknowledge the support received from Element Energy, the energy consultancy in the UK.

\section{REFERENCES}

[1] Muhssin, M. T., Cipcigan, L. M., Obaid, Z. A., \& Al-Ansari, W. F. (2017). A novel adaptive deadbeat- based control for load frequency control of low inertia system in interconnected zones north and south of Scotland. International Journal of Electrical Power \& Energy Systems, 89(7), 52-61. https://doi.org/10.1016/j.jiepes.2016.12.005

[2] Bevrani, H. (2014). Robust power system frequency control. New York: Springer. https://doi.org/10.1007/978-3-319-07278-4

[3] Muhssin, M. T., Cipcigan, L. M., \& Obaid, Z. A. (2015). Small Microgrid stability and performance analysis in isolated island. The $50^{\text {th }}$ International Universities Power Engineering Conference (UPEC), 1-6. https://doi.org/10.1109/UPEC.2015.7339911

[4] Kovacs, L., Drenyovsazki, R., Olah, A., Levendovszky, J., Tornai, K., \& Pinter, I. (2017). A probabilistic demand side management approach by consumption admission control. Tehnički vjesnik, 24(1), 199-207. https://doi.org/10.17559/TV-20151021201400

[5] Strbac, G. (2008). Demand side management: Benefits and challenges. Energy Policy, 36(12), 4419-4426. https://doi.org/10.1016/j.enpol.2008.09.030 
[6] (2011). Module 14, Demand-side management. Sustainable Energy Regulation and Policymaking for Africa, http://africa-toolkit.reeep.org/modules/Module14.pdf

[7] Weckx, S., Hulst, R. D., \& Driesen, J. (2015). Primary and Secondary Frequency Support by a Multi-Agent Demand Control System. IEEE Transactions on Power Systems, 30, 1394-1404. https://doi.org/10.1109/TPWRS.2014.2340582

[8] Molina-Garcia, A., Bouffard, F., \& Kirschen, D. S. (2011). Decentralized Demand-Side Contribution to Primary Frequency Control. IEEE Transactions on Power Systems, 26, 411-419. https://doi.org/10.1109/TPWRS.2010.2048223

[9] Eto, J. H., Nelson-Hoffman, J., Parker, E., Bernier, C., Young, P., Sheehan, D., et al. (2012). The Demand Response Spinning Reserve Demonstration--Measuring the Speed and Magnitude of Aggregated Demand Response. The $45^{\text {th }}$ Hawaii International Conference on System Science (HICSS2012), 2012-2019.

[10] (2014). The Parliamentary Office of Science and Technology. Electricity Demand-Side Response. January 2014.

http://researchbriefings.parliament.uk/ResearchBriefing/Su mmary/POST-PN-452

[11] Hong, J. (2009). The Development, Implementation, and Application of Demand Side Management and control $(\mathrm{DSM}+\mathrm{c})$ Algorithm for Integrating Microgeneration System within Built Environment. PhD thesis, Department of Mechanical Engineering, University of Strathclyde.

[12] Short, J. A., Infield, D. G., \& Freris, L. L. (2007). Stabilization of Grid Frequency through Dynamic Demand Control. IEEE Transactions on Power Systems, 22, 12841293. https://doi.org/10.1109/TPWRS.2007.901489

[13] Borg, S. P., Kelly, N. J., Markopoulos, A., Strachan, P. A., Porteous, C., \& Sharpe, T. (2011). Communal residential laundry washing and drying- can it provide demand-side electrical load flexibility? The $2^{\text {nd }}$ International conference in microgeneration and related technologies, Glasgow.

[14] Ali, M., Jokisalo, J., Siren, K., \& Lehtonen, M. (2014). Combining the Demand Response of direct electric space heating and partial thermal storage using LP optimisation. Electric Power Systems Research, 106(1), 160-167. https://doi.org/10.1016/j.epsr.2013.08.017

[15] Drysdale, B., Wu, J., \& Jenkins, N. (2015). Flexible demand in the GB domestic electricity sector in 2030. Applied Energy, 139(2/1), 281-290.

[16] (2015). Frequency Sensitive Electric Vehicle and Heat Pump Power Consumption. Element Energy, July $17^{\text {th }} 2015$.

[17] (2015). National Grid, Future Energy Scenarios.

[18] Element Energy. Pathways to high penetration of heat pumps. Oct. 2012, [Online]. Available: https://www.theccc.org.uk/wpcontent/uploads/2013/12/Frontier-Economics-ElementEnergy-Pathways-to-high-penetration-of-heat-pumps.pdf

[19] Rasmussen, C. N., Rasmussen, C. B., Palivan, S., \& Bogo, R. (2014). Heating Demand as Frequency Controlled Regulation Power. International Journal of Energy and Power (IJEP), 3, 22-33.

[20] Xu, Z., Ostergaard, J., Togeby, M., \& Marcus-Moller, C. (2007). Design and Modelling of Thermostatically Controlled Loads as Frequency Controlled Reserve. IEEE Power Engineering Society General Meeting, 1-6. https://doi.org/10.1109/PES.2007.386014

[21] Biegel, B., Hansen, L. H., Andersen, P., \& Stoustrup, J. (2013). Primary Control by ON/OFF Demand-Side Devices. IEEE Transactions on Smart Grid, 4, 2061-2071.

[22] Blecich, P., Bonefačić, I., \& Wolf, I. (2017). Space heating and cooling energy demand in energy efficient single-family house with mechanical ventilation system. Tehnički vjesnik, 24(Supplement 1), 119-126. https://doi.org/10.17559/TV-20150112153930
[23] Bagdanavicius, A. \& Jenkins, N. (2013). Power requirements of ground source heat pumps in a residential area. Applied Energy, 102(2), 591-600. https://doi.org/10.1016/j.apenergy.2012.08.036

[24] Muhssin, M. T., Cipcigan, L. M., Jenkins, N., Meng, C., \& Obaid, Z. A. (2016). Modelling of a population of Heat Pumps as a Source of load in the Great Britain power system. International Conference on Smart Systems and Technologies (SST), 109-113. https://doi.org/10.1109/SST.2016.7765642

[25] Science and Engineering Encyclopaedia. Heat Pump. http://www.diracdelta.co.uk/science/source/h/e/heat\%20pu $\mathrm{mp} /$ source.html\#.WLW0xO1SCUk (Accessed on 10.02.2016)

[26] Cambray, J. T. (2009). Domestic air source heat pump technology and policy - heating the future? MSc Thesis, Cardiff University, UK.

[27] Cantor, J. (2001). Heat pumps for the home. Ramsbury : Crowood Press.

[28] Lu, N. (2012). An Evaluation of the HVAC Load Potential for Providing Load Balancing Service. IEEE Transactions on Smart Grid, 3, 1263-1270. https://doi.org/10.1109/TSG.2012.2183649

[29] Hong, J., Kelly, N. J., Richardson, I., \& Thomson, M. (2012). Assessing heat pumps as flexible load. Proc Inst Mech Eng Part A Power Energy, 227, 30-42. https://doi.org/10.1177/0957650912454830

\section{Contact information:}

Mazin MUHSSIN, PhD student

Cardiff University, Electrical and Electronic Engineering Queen's Buildings, The Parade, Cardiff, CF24 3AA, UK

E-mail: MuhssinMT@cardiff.ac.uk

E-mail: mazinthany2004@gmail.com

Liana CIPCIGAN, Dr. Reader

Cardiff University, Electrical and Electronic Engineering Queen's Buildings, The Parade, Cardiff, CF24 3AA, UK

E-mail: CipciganLM@cardiff.ac.uk

\section{Nick JENKINS, Dr. Professor}

Cardiff University, Electrical and Electronic Engineering Queen's Buildings, The Parade, Cardiff, CF24 3AA, UK

E-mail: JenkinsN6@cardiff.ac.uk

\section{Meng CHENG, Dr.}

Cardiff University, Electrical and Electronic Engineering Queen's Buildings, The Parade, Cardiff, CF24 3AA, UK E-mail: ChengM2@cardiff.ac.uk

\section{Zeyad OBAID, PhD student}

Cardiff University, Electrical and Electronic Engineering Queen's Buildings, The Parade, Cardiff, CF24 3AA, UK E-mail: Al-ObaidiZA@cardiff.ac.uk 